\title{
The matrix component biglycan is proinflammatory and signals through Toll-like receptors 4 and 2 in macrophages
}

\author{
Liliana Schaefer, ${ }^{1}$ Andrea Babelova,, ${ }^{1}$ Eva Kiss, ${ }^{2}$ Heinz-J. Hausser, ${ }^{3}$ Martina Baliova, ${ }^{1}$ \\ Miroslava Krzyzankova, ${ }^{1}$ Gunther Marsche, ${ }^{4}$ Marian F. Young, ${ }^{5}$ Daniel Mihalik, ${ }^{1}$ Martin Götte, ${ }^{6}$ \\ Ernst Malle, ${ }^{4}$ Roland M. Schaefer, ${ }^{1}$ and Hermann-Josef Gröne ${ }^{2}$

\begin{abstract}
'Department of Medicine D, Interdisciplinary Center of Clinical Research, Muenster, University of Muenster, Muenster, Germany. ${ }^{2}$ Department of Cellular and Molecular Pathology, German Cancer Research Center, Heidelberg, Germany. ${ }^{3}$ Division for Biochemistry of Joint and Connective Tissue Diseases, University of Ulm, Ulm, Germany. ${ }^{4}$ Institute of Molecular Biology and Biochemistry, Medical University Graz, Graz, Austria. ${ }^{5}$ Craniofacial and Skeletal Diseases Branch, National Institute of Dental and Craniofacial Research, NIH, Bethesda, Maryland, USA.
\end{abstract} \\ ${ }^{6}$ Department of Gynecology, Muenster University Hospital, Muenster, Germany.
}

\begin{abstract}
Biglycan, a small leucine-rich proteoglycan, is a ubiquitous ECM component; however, its biological role has not been elucidated in detail. Here we show that biglycan acts in macrophages as an endogenous ligand of TLR4 and TLR2, which mediate innate immunity, leading to rapid activation of p38, ERK, and NF- $K B$ and thereby stimulating the expression of TNF- $\alpha$ and macrophage inflammatory protein-2 (MIP-2). In agreement, the stimulatory effects of biglycan are significantly reduced in TLR4-mutant (TLR4-M), TLR2-/-, and myeloid differentiation factor $88^{-/-}\left(\mathrm{MyDS8}^{-/-}\right)$macrophages and completely abolished in TLR2-/-/TLR4-M macrophages. Biglycan-null mice have a considerable survival benefit in LPS- or zymosan-induced sepsis due to lower levels of circulating TNF- $\alpha$ and reduced infiltration of mononuclear cells in the lung, which cause less end-organ damage. Importantly, when stimulated by LPS-induced proinflammatory factors, macrophages themselves are able to synthesize biglycan. Thus, biglycan, upon release from the ECM or from macrophages, can boost inflammation by signaling through TLR4 and TLR2, thereby enhancing the synthesis of TNF- $\alpha$ and MIP-2. Our results provide evidence for what is, to our knowledge, a novel role of the matrix component biglycan as a signaling molecule and a crucial proinflammatory factor. These findings are potentially relevant for the development of new strategies in the treatment of sepsis.
\end{abstract}

\section{Introduction}

Biglycan (BGN), a member of the family of small leucine-rich proteoglycans (SLRPs), consists of a core protein and a chondroitin/ dermatan sulfate chain(s) (1). Although it is abundant in many tissues, its biological functions remain poorly understood. BGN is considered to have an organizing role in the assembly of the ECM. Targeted disruption of the BGN gene results in abnormal collagen fibril morphology (2) and an osteoporosis-like phenotype (3). BGN is also directly involved in cell signaling. By regulating the interaction of bone morphogenic protein- 4 with its inhibitor chordin, it modulates signaling of this morphogen (4). Furthermore, BGN may affect signal transduction during cell growth and differentiation via induction of the cyclin-dependent kinase inhibitor $\mathrm{p} 27^{\mathrm{KIP}}$ (5). BGN-induced activation of RhoA and Rac1 signaling increases migration of lung fibroblasts (6). Moreover, adenovirus-mediated gene transfer of BGN induced a fibroblastic response in the lung, indicating a role of $\mathrm{BGN}$ in fibrogenesis (7).

Nonstandard abbreviations used: BGN, biglycan; b.wt., body weight; EMSA, electrophoretic mobility shift assay; ESI/MS/MS, electrospray ionization tandem mass spectrometry; GAG, glycosaminoglycan; MD-2, myeloid differentiation protein-2; MEK1/2, mitogen-activated protein kinase kinase 1 and 2; MIP-2, macrophage inflammatory protein-2; MyD88, myeloid differentiation factor 88; PAMP, pathogenassociated molecular pattern; SEB, staphylococcal enterotoxin B; SLRP, small leucinerich proteoglycan; SR-AI, scavenger receptor class A type I; TLR4-M, TLR4 mutant. Conflict of interest: The authors have declared that no conflict of interest exists.

Citation for this article: J. Clin. Invest. 115:2223-2233 (2005). doi:10.1172/JCI23755.
There is growing evidence that ECM molecules may convey proinflammatory signals (8-13). Previously, we reported increased expression of BGN in renal inflammation, associated with heavy infiltration of BGN-expressing macrophages (14). More recent data indicated that BGN expression is regulated by nitric oxide in monocyte-like mesangial cells (15). Based on its capacity to bind TGF- $\beta$ (16) and TNF- $\alpha$ (17), BGN may be involved in regulating cytokine activity. BGN seems to be required for growth and differentiation of monocytic-lineage cells (18). Like other gene products involved in pathogen recognition (TLRs, resistance genes in plants, CD14, nucleotide-binding oligomerization domain proteins) (19, $20)$, the BGN core protein contains leucine-rich repeats that facilitate protein-protein interactions (1). Recently, binding of BGN to the scavenger receptor class A (SR-A) and the endocytic mannose receptor $(21,22), 2$ pattern recognition receptors on macrophages (23), has been reported. Therefore, we investigated whether BGN is part of the innate immune system and a potential innate antigen analogous to pathogen-associated molecular patterns (PAMPs).

TLRs are seminal immune receptors that are capable of sensing PAMPs of organisms ranging from protozoa to bacteria, fungi, and viruses $(24,25)$. The inflammatory response of macrophages to LPS is mediated mainly by a receptor complex composed of TLR4, CD14, and myeloid differentiation protein-2 (MD-2) (24, 26-28), which is critically important in innate immune recognition of Gram-negative pathogens. TLR2 participates in the recognition of Gram-positive bacteria, peptidoglycan, and yeast zymosan (24). Although TLR4 and TLR2 are highly specific in their pathogen 
A
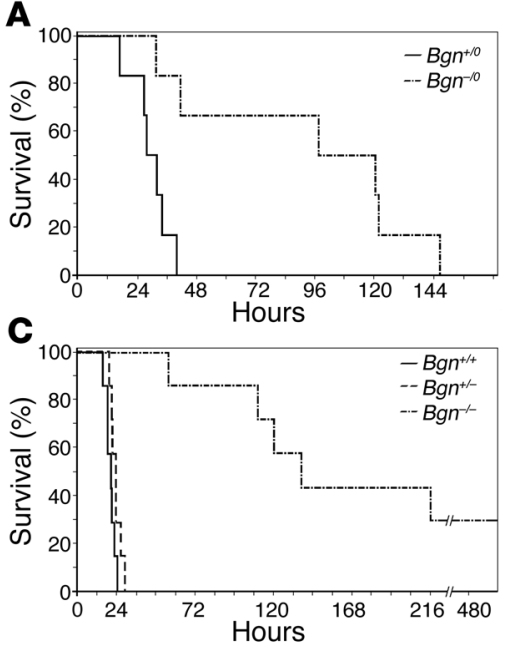
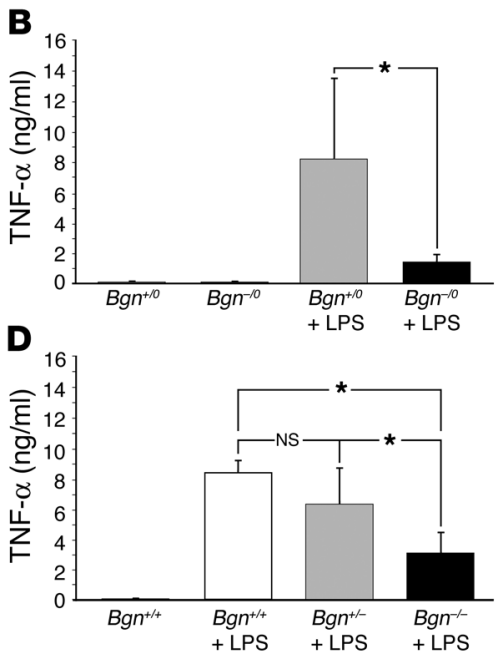

\section{Figure 1}

Bgn deficiency improved survival and lowered plasma levels of TNF- $\alpha$ in mice with LPS-induced sepsis. (A and C) Survival of male $\mathrm{Bgn}^{-10}$ and $B g n^{+/ 0}$ mice $(n=6)(\mathbf{A})$ and female $\mathrm{Bgn}^{+/+}, \mathrm{Bgn}^{+/-}$, and $\mathrm{Bgn}^{-/-}$mice $(n=7)(\mathbf{C})$ after a lethal dose of LPS. Two of the $\mathrm{Bgn}^{-/-}$mice survived. (B and D) Plasma levels of TNF- $\alpha$ in male control mice without LPS $\left(\mathrm{Bgn}^{+/ 0}\right.$ and $\mathrm{Bgn}^{-10}$, each group $\left.n=3\right)$ and in $\mathrm{Bgn}^{+/ 0}(n=5)$ and $\mathrm{Bgn}^{-10}$ mice $(n=4) 90$ minutes after a sublethal dose of LPS (B) and in female control $\mathrm{Bgn}^{+/+}$ mice without LPS and in $\mathrm{Bgn}^{+/+}, \mathrm{Bgn}^{+/}$, and $\mathrm{Bgn}^{-/-}$mice (each group $n=3$ ) 90 minutes after a sublethal dose of LPS (D). Data are given as means \pm SD. ${ }^{*} P<0.05$. recognition and activation of signal transduction, they share a common signaling pathway $(20,24)$ involving an intracellular adapter protein called myeloid differentiation factor 88 (MyD88) (29), rapid phosphorylation of ERK (30) and p38 (31), and rapid downstream activation of NF- $\mathrm{KB}(32)$, which lead to the expression of TNF- $\alpha$ and macrophage inflammatory protein-2 (MIP-2) (20).

Here we demonstrate that biglycan-null (Bgn-null) mice have a considerable survival benefit in LPS- or zymosan-induced sepsis, due to lower levels of circulating TNF- $\alpha$ and reduced infiltration of mononuclear cells in the lungs. In macrophages, BGN induced signaling through TLR4 and TLR2, leading to rapid activation of $\mathrm{p} 38, \mathrm{ERK}$, and NF- $\mathrm{KB}$ and finally to a pronounced expression of TNF- $\alpha$ and MIP-2. This study provides evidence that BGN is a secretory product of macrophages that can act as a "danger" motif analogous to PAMPs, exerting proinflammatory functions by signaling through TLR4 and TLR2.

\section{Results}

Improved survival of Bgn-deficient mice in LPS-induced sepsis. To investigate the influence of BGN on systemic inflammation, sepsis was induced in female $\mathrm{Bgn}^{+/+}, \mathrm{Bg} n^{+/-}$, and $\mathrm{Bgn}^{-/-}$mice and in male $\mathrm{Bg} n^{+/ 0}$ and $B g n^{-/ 0}$ mice by i.p. injection of LPS. On average, 8 -week-old $B g n^{+/ 0}$ mice died at $30 \pm 8$ hours after injection, while $B g n^{-10}$ animals survived for $95 \pm 19$ hours $(n=6, P<0.05)$ (Figure $1 \mathrm{~A})$. Ninety minutes after injection of LPS, plasma TNF- $\alpha$ levels were 6 times lower in $B g n^{-/ 0}$ mice than in WT animals, while $B g n^{-/ 0}$ and $B g n^{+/ 0}$ mice not treated with LPS had identical plasma levels of TNF- $\alpha$ (Figure 1B). Similarly, female Bgn ${ }^{+/+}$mice died much earlier $(20 \pm 2$ hours, $n=7)$ than $B g n^{-/-}$mice $(127 \pm 39 \mathrm{~h}, n=5, P<0.05)$, of which 2 animals even survived the treatment (Figure 1C). Again, improved survival was associated with lower plasma levels of TNF- $\alpha$ (Figure 1D). However, $\mathrm{Bgn}^{+/-}$mice had no survival benefit ( $23 \pm 2$ hours, $n=7, P>0.05$ ) (Figure 1C), and TNF- $\alpha$ plasma levels were not significantly different from those in $B g n^{+/+}$mice (Figure 1D). Thus, a lack of BGN prolongs survival of septic animals, probably by tempering the inflammatory cytokine response to endotoxin.

Increased expression of BGN attracts infiltrating cells to the lung parenchyma in sepsis. To test whether BGN expression increases during septic inflammation in the lung, a major target organ in sepsis, $B g n^{+/ 0}$ mice were injected with a lethal dose of LPS. BGN mRNA (1.7 \pm 0.2 times control, $n=3, P<0.05,2$ hours of sepsis) (Figure
$2 \mathrm{~A})$ and protein $(1.6 \pm 0.3$ times control, $n=4, P<0.05$, 8 hours of sepsis) (Figure 2B) were increased in septic lungs compared with lungs from healthy mice. Immunostaining (Figure 2, C and D) and in situ hybridization confirmed these results and revealed macrophages as a source of BGN protein (Figure 2E) and mRNA expression (Figure 2F) in septic lungs. We previously demonstrated an association of increased expression of BGN with enhanced infiltration of mononuclear cells (14). Therefore, absence of BGN might reduce inflammatory cell infiltration in septic lungs. Indeed, we found significantly fewer infiltrating mononuclear cells in the lungs of septic $B g n^{-10}$ (Figure $2 \mathrm{H}$ ) compared with $B g n^{+/ 0}$ mice (Figure $2 \mathrm{G}$ ), as quantified by $\mathrm{H} \& \mathrm{E}$ staining and by $\mathrm{F} 4 / 80$ immunostaining (Table 1). The improved outcome of sepsis in $B g n^{-/ 0}$ mice cannot be attributed to a compensatory overexpression of decorin or fibromodulin in these animals (33), as immunostainings for SLRPs both in the lung and in the liver revealed no differences from those in WT mice (data not shown). Furthermore, type I collagen (Figure 2, I and J), fibronectin (Figure 2K), laminin (Figure $2 \mathrm{~L}$ ), and type VI collagen (not shown), all known to augment the adhesiveness of leukocytes $(34,35)$, were equally increased in septic lungs from $B g n^{+/ 0}$ and $B g n^{-/ 0}$ mice.

LPS-triggered IL-1 $\beta$ and IL-6 lead to BGN expression, and BGN induces TNF- $\alpha$ and MIP-2 in macrophages. Given that BGN was increased in LPS-septic lungs and macrophages acted as a source of BGN, we investigated whether BGN is produced by macrophages only during infection, and if so, what stimuli would trigger its synthesis. As the $B G N$ promoter region contains an IL-6-responsive element (36), we hypothesized that LPS-induced proinflammatory cytokines may trigger BGN expression. LPS stimulation (1 hour) resulted in an equal increase of IL-6 (Figure 3A) and IL-1 $\beta$ (Figure 3B) levels in culture media from both $B g n^{+/ 0}$ and $B g n^{-/ 0}$ thioglycollate-elicited peritoneal macrophages. Unstimulated macrophages did not express BGN mRNA (Figure 3C) or protein (Figure 3D). However, upon stimulation with IL-1 $\beta$ or IL-6, WT macrophages expressed BGN mRNA (Figure 3C) and secreted BGN protein (Figure 3D).

As the rise in circulating TNF- $\alpha$ was blunted in septic Bgn-deficient mice, we subsequently investigated whether BGN influences the expression of TNF- $\alpha$ and MIP-2. Incubation of peritoneal macrophages from $B g n^{+/ 0}$ and $B g n^{-10}$ mice with BGN for 6 hours led to increased mRNA levels of TNF- $\alpha\left(B g n^{+/ 0}\right.$ plus BGN: $5.5 \pm 0.6$ times $B g n^{+/ 0} ; B g n^{-/ 0}$ plus BGN: $3.3 \pm 0.4$ times $\left.B g n^{-/ 0} ; n=3, P<0.05\right)$ and 

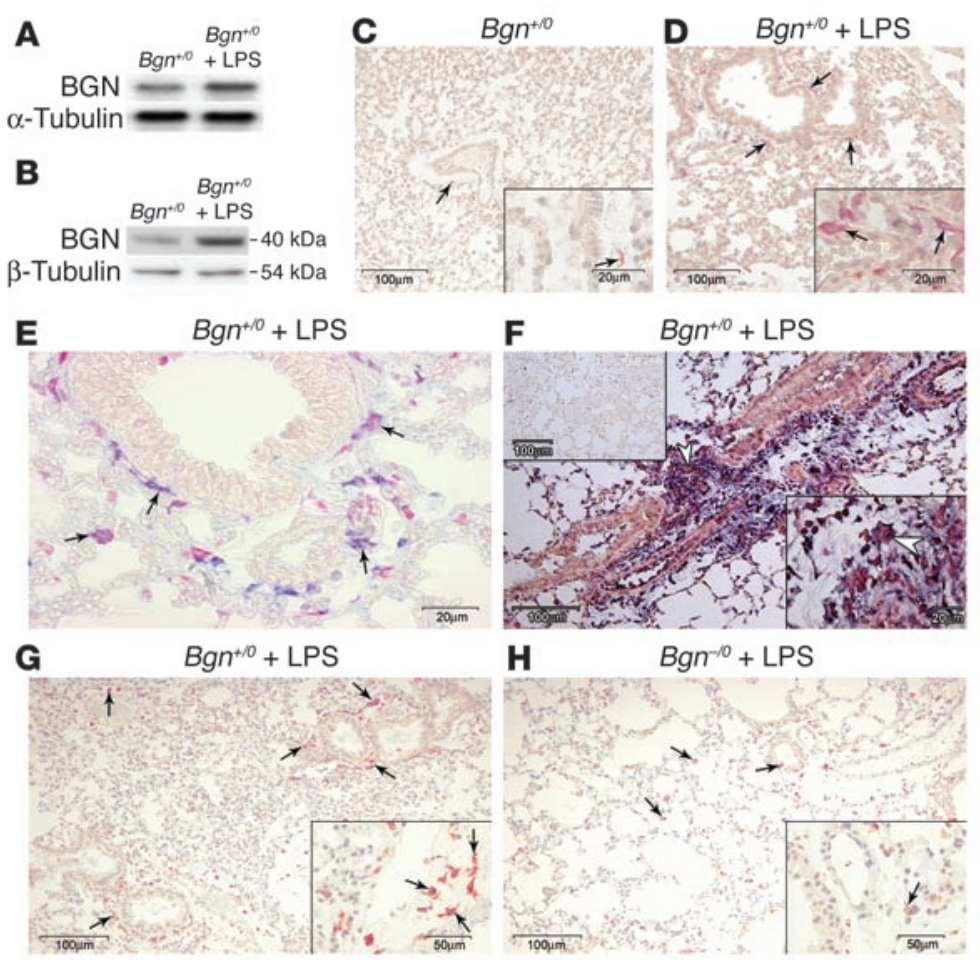

H $\quad \mathrm{Bgn}^{-10}+$ LPS
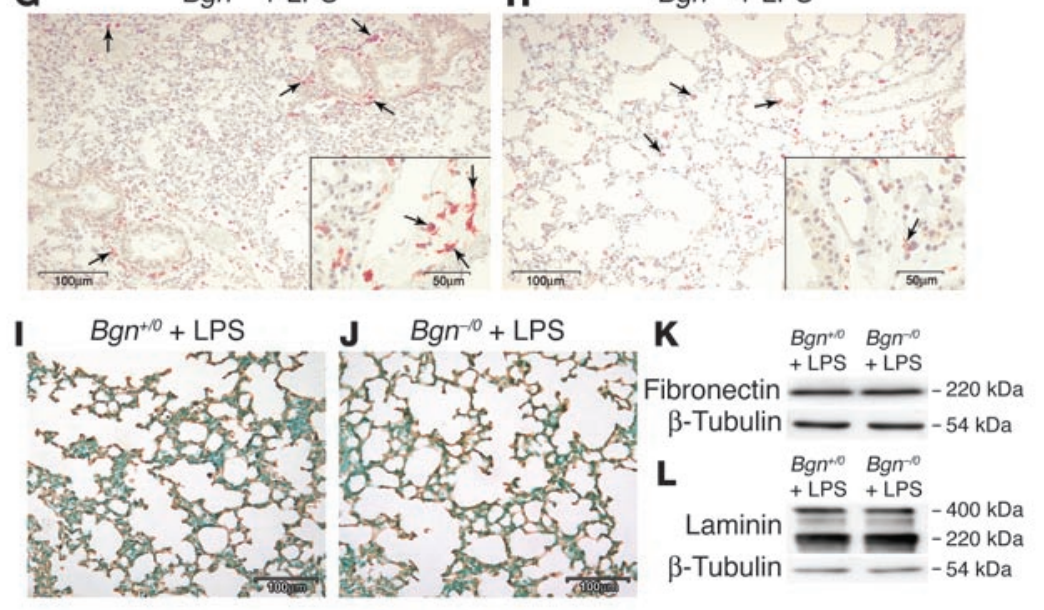

\section{Figure 2}

Increased expression of $B G N$ in infiltrating cells of lung parenchyma in sepsis. (A and B) Northern blot of BGN mRNA normalized to $\alpha$-tubulin (2 hours) (A) and Western blot of BGN core protein normalized to $\alpha$-tubulin (8 hours) (B) from lungs of $\mathrm{Bgn}^{+/ 0}$ mice after a lethal dose of LPS versus PBS. (C and D) Immunostaining of BGN (red stain) in lungs from control (C) and septic $\mathrm{Bgn}^{+10}$ mice (D) 8 hours after a lethal dose of LPS. (E and F) Double staining, marked by arrows, for BGN (blue) and macrophages (F4/80, red) $(E)$ and in situ hybridization for BGN $(\mathbf{F})$ in septic lungs from $\mathrm{Bgn}^{+/ 0}$ mice (8 hours). The lower right inset shows a magnified view of mononuclear cells expressing BGN (white arrowhead). The upper left inset represents the sense riboprobe. ( $\mathbf{G}$ and $\mathbf{H})$ Immunostaining of macrophages (F4/80, red), with numerous F4/80-positive macrophages (lower right insets), in septic lungs from $\mathrm{Bgn}^{+/ 0}$ (G) versus $\mathrm{Bgn}^{-10}$ mice (H). (I-L) Immunostaining of type I collagen in lungs from $\mathrm{Bgn}^{+/ 0}$ (brown) (I) versus $B g n^{-10}$ mice $(\mathbf{J})$ and Western blots of fibronectin $(\mathbf{K})$ and laminin (L) normalized to $\beta$-tubulin in lungs from $\mathrm{Bgn}^{+/ 0}$ versus $\mathrm{Bgn}^{-10}$ mice 8 hours after a lethal dose of LPS. The lower right insets in $\mathbf{C}, \mathbf{D}, \mathbf{F}, \mathbf{G}$, and $\mathbf{H}$ represent higher magnifications. Scale bars in $\mathbf{D}, \mathbf{H}$, and $\mathbf{J}$ apply to panels in $\mathbf{C}, \mathbf{G}$, and $\mathbf{I}$, respectively.
MIP-2 $\left(B g n^{+/ 0}\right.$ plus BGN: $3.3 \pm 0.6$ times $B g n^{+/ 0} ; B g n^{-/ 0}$ plus BGN: $1.9 \pm 0.2$ times $B g n^{-/ 0} ; n=3, P<0.05$ ) (Figure $3 \mathrm{E}$ ). When macrophages from $B g n^{+/ 0}$ and $B g n^{-/ 0}$ mice were cultured for 2-24 hours in the presence or absence of BGN, we found dose-dependent (Figure $3, \mathrm{~F}$ and $\mathrm{G}$ ) and time-dependent increases of secreted (shown for TNF- $\alpha$ in Figure $3 \mathrm{H}$ ) as well as cellular TNF- $\alpha$ and MIP-2 (TNF- $\alpha$ : $1.6 \pm 0.4$ times control [without BGN] $, n=5, P<0.05$; MIP- $2: 23 \pm 11$ times control [without $\mathrm{BGN}$ ], $n=3, P<0.05$ after incubation of $B g n^{+/ 0}$ macrophages with $10 \mu \mathrm{g} / \mathrm{ml} \mathrm{BGN}$ for 24 hours). BGN-mediated increases of TNF- $\alpha$ and MIP-2 expression and secretion (Figure 3, E-H) appeared to be slightly (though not significantly) lower in $B g n^{-10}$ than in $B g n^{+/ 0}$ macrophages, possibly because of binding of the exogenously added BGN to additional binding sites that are partially occupied by endogenous BGN in $B g n^{+/ 0}$ macrophages. Importantly, though the LPS-mediated increases of TNF- $\alpha$ and MIP-2 expression and secretion (Figure 3, I and J) were significantly lower in $B g n^{-10}$ than in $B g n^{+/ 0}$ macrophages, the differences were not as pronounced as in the in vivo situation (Figure 1B). Thus, it appears that in isolated macrophages LPS initially triggers IL- $1 \beta$ and IL- 6 expression, which then leads to BGN expression with a subsequent induction of TNF- $\alpha$ and MIP-2. Under in vivo conditions, LPS effects may be further aggravated by liberation of BGN from the ECM (due to the activity of proteolytic enzymes in the course of sepsis), further enhancing the induction of TNF- $\alpha$ and MIP-2 expression in macrophages. Data confirming the specificity and requirement of the intact and soluble BGN molecule for induction of macrophages are shown in Supplemental Figure 1 (supplemental material available online with this article; doi:10.1172/JCI23755DS1).

$B G N$ activates $p 38, E R K$, and $N F-\kappa B$ in macrophages. Subsequently, potential intracellular signaling cascades by which BGN stimu-

\section{Table 1}

Quantification of mononuclear cells in septic lungs of $\mathrm{Bgn}^{+/ 0}$ and Bgn $^{-10}$ mice

\begin{tabular}{lcccc}
\hline $\boldsymbol{n}$ & $\begin{array}{c}\text { Mononuclear cells } \\
\text { (H\&E staining) }\end{array}$ & $\boldsymbol{n}$ & $\begin{array}{c}\text { Macrophages } \\
\text { (F4/80 staining) }\end{array}$ \\
$B g n^{+/ 0}$ & 9 & $3.1 \pm 1.2$ & 6 & $2.9 \pm 0.8$ \\
$B g n^{-10}$ & 9 & $3.3 \pm 1.6$ & 6 & $2.9 \pm 1.3$ \\
$B g n^{+/ 0}+$ LPS & 9 & $43.5 \pm 12.6^{\mathrm{A}}$ & 5 & $34.1 \pm 3.2^{\mathrm{A}}$ \\
$\mathrm{Bgn}^{-10}+$ LPS & 9 & $23.0 \pm 9.4^{\mathrm{B}, \mathrm{C}}$ & 5 & $16.9 \pm 3.2^{\mathrm{B}, \mathrm{C}}$ \\
$\mathrm{Bgn}^{+/ 0}+$ zymosan & 5 & $27.9 \pm 1.2^{\mathrm{A}}$ & 5 & $13.6 \pm 4.7^{\mathrm{A}}$ \\
Bgn $^{-10}+$ zymosan & 5 & $13.2 \pm 1.8^{\mathrm{B}, \mathrm{D}}$ & 5 & $6.9 \pm 1.6^{\mathrm{B}, \mathrm{D}}$ \\
\hline
\end{tabular}

Data are given as means $\pm \mathrm{SD}$. H\&E-stained mononuclear cells and F4/80-positive macrophages were quantified in at least 15 high-power fields ( $\times 400$ ) per section. AP $<0.05$ for $\mathrm{Bgn}^{+/ 0}+\mathrm{LPS}$ or $\mathrm{Bgn}^{+/ 0}+$ zymosan versus $B g n^{+10} ; B P<0.05$ for $B g n^{-10}+$ LPS or $B g n^{-10}+$ zymosan versus $B g n^{-10} ; C P<0.05$ for $B g n^{-10}+$ LPS versus $B g n^{+10}+$ LPS; $D P<0.05$ for $\mathrm{Bgn}^{-10}+$ zymosan versus $\mathrm{Bgn}^{+/ 0}+$ zymosan. 

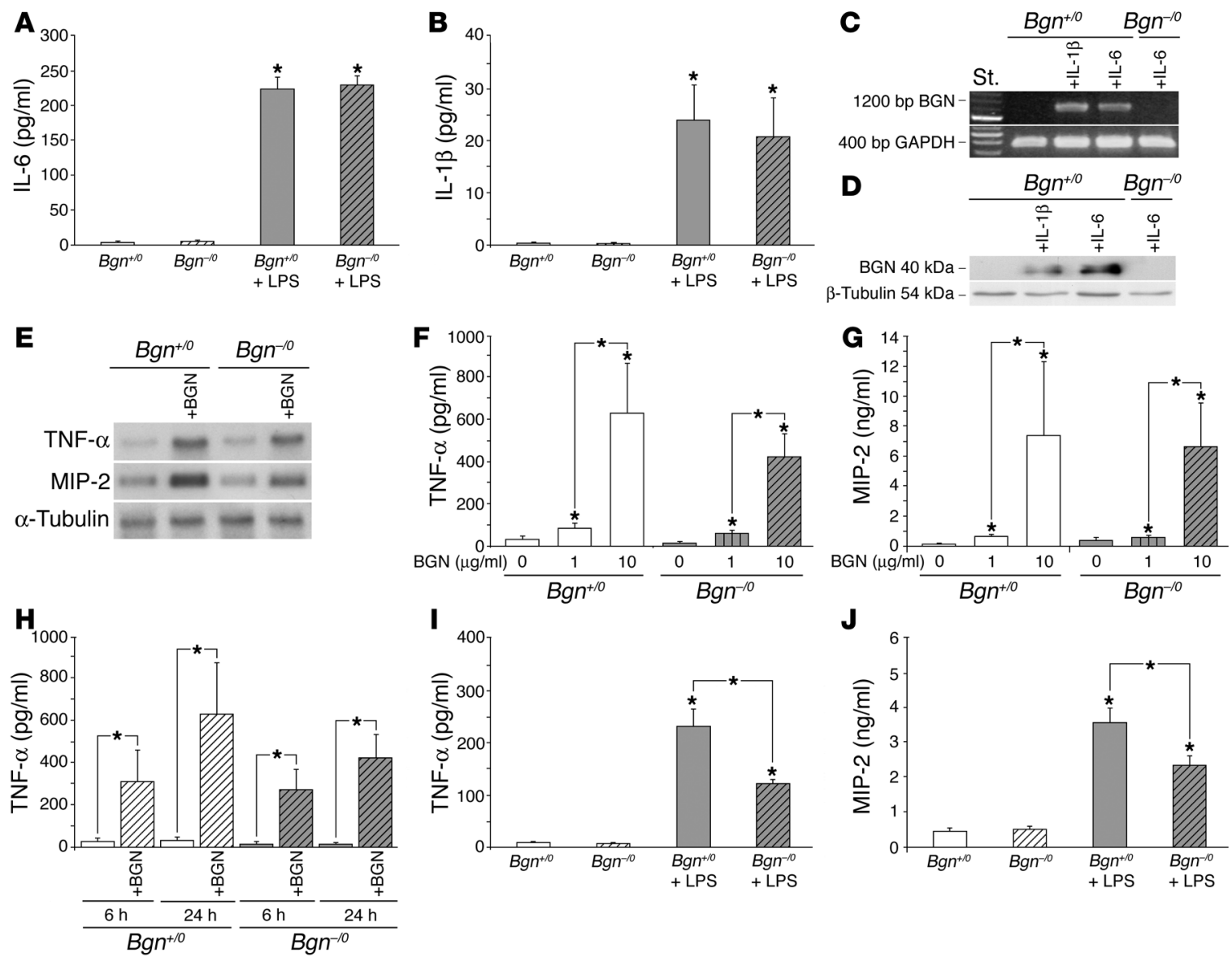

Figure 3

LPS-stimulated macrophages secrete IL- 6 and IL-1 $\beta$, both of which induce the expression of BGN, which in turn stimulates TNF- $\alpha$ and MIP-2 mRNA and protein expression in macrophages. (A and B) ELISA for IL-6 (A) and IL-1 $\beta$ (B) in culture media from $\mathrm{Bgn}^{+/ 0}$ and $\mathrm{Bgn}^{-10} \mathrm{macrophages}$ left unstimulated or stimulated with $0.5 \mathrm{ng} / \mathrm{ml}$ LPS for 1 hour. (C and D) RT-PCR of BGN mRNA (C) and Western blot of BGN core protein (D) secreted into culture media from $\mathrm{Bgn}^{+/ 0}$ and $\mathrm{Bgn}^{-10}$ macrophages 2 hours after stimulation with either IL-6 or IL-1 $\beta$ (both $\left.10 \mathrm{ng} / \mathrm{ml}\right)$, normalized to GAPDH or $\beta$-tubulin, respectively. (E) Northern blots of TNF- $\alpha$ and MIP-2 mRNA (normalized to $\alpha$-tubulin) in $\mathrm{Bgn}^{+/ 0}$ and $B g n^{-10}$ macrophages after 6 hours of incubation with BGN $(4 \mu \mathrm{g} / \mathrm{ml})$. (F and $\mathbf{G})$ Dose-dependent enhancement of TNF- $\alpha(\mathbf{F})$ and MIP-2 (G) concentrations in media from $\mathrm{Bgn}^{+/ 0}$ or $\mathrm{Bgn}^{-10}$ macrophages cultured for 24 hours in the absence or presence of BGN (1 or $\left.10 \mu \mathrm{g} / \mathrm{ml}\right)$. (H) Time-dependent enhancement of TNF- $\alpha$ concentrations in media from $\mathrm{Bgn}^{+/ 0}$ or $\mathrm{Bgn}^{-10}$ macrophages cultured for 6 and 24 hours in the absence or presence of BGN (10 $\mu \mathrm{g} / \mathrm{ml}$ ). (I and J) ELISA for TNF- $\alpha$ (I) and MIP-2 (J) in media from Bgn ${ }^{+/ 0}$ or $\mathrm{Bgn}^{-10}$ macrophages cultured for 6 hours in the absence or presence of LPS $(0.5 \mathrm{ng} / \mathrm{ml})$. Data are given as means \pm SD from 3-7 animals. ${ }^{*} P<0.05$ for macrophages with versus without BGN or LPS, respectively.

lates TNF- $\alpha$ and MIP-2 expression in macrophages were explored. Within 10 minutes of incubation, BGN enhanced phosphorylation of ERK $(3.5 \pm 0.6$ times control without BGN, $n=3, P<0.05)$ and p38 $(2.4 \pm 0.5$ times control, $n=3, P<0.05)$ in thioglycollate-stimulated $B g n^{+/ 0}$ macrophages, reaching a maximum after 30 minutes (p-ERK/ERK: $5.1 \pm 0.4$ times control without BGN; p-p38/p38: $3.5 \pm 0.6$ times control without BGN; each $n=3$, $P<0.05$ ) with a return to normal levels within 120 minutes (Figure 4A). Preincubation of macrophages for 1 hour with U0126, a specific inhibitor of mitogen-activated protein kinase kinase 1 and 2 (MEK1/2), completely abolished ERK phosphorylation (Figure 4B) after 30 minutes. Furthermore, both U0126 and SB203580, an inhibitor of p38 phosphorylation, caused a significant reduction of BGN-induced secretion of TNF- $\alpha$ and MIP-2 into the culture media from BGN-stimulated macrophages after 6 hours (Figure 4, $\mathrm{C}$ and D). Finally, enhanced activation of NF- $\mathrm{\kappa B}$ after 30 minutes of incubation with BGN was shown by electrophoretic mobility shift assay (EMSA) (Figure 4E). Taken together, these results show that the BGN-dependent induction of TNF- $\alpha$ and MIP-2 in macrophages involves the ERK, $\mathrm{p} 38$, and NF-кB pathways.

BGN signals through TLR4 and TLR2 in macrophages. The effect of BGN on HEK293 cells, which functionally expressed human TLR2, $-3,-4,-5,-7,-8$, or -9 and an alkaline phosphatase gene under control of the IL-12p40 promoter, was tested. When 10 $\mu \mathrm{g} / \mathrm{ml} \mathrm{BGN}$ was used, only activation of TLR 2 and TLR4 was observed (Figure 5A). A dose-response analysis showed that 10 $\mu \mathrm{g} / \mathrm{ml} \mathrm{BGN}$ stimulates TLR4 (Figure 5B) and TLR2 (Figure 5C) to the same extent that $10 \mathrm{ng} / \mathrm{ml} \mathrm{FSL-1} \mathrm{stimulates} \mathrm{TLR2} \mathrm{or} 1 \mathrm{ng} / \mathrm{ml}$ LPS-K12 stimulates TLR4.

Preincubation of macrophages from $B g n^{+/ 0}$ and $B g n^{-/ 0}$ mice with blocking anti-TLR4 antibodies significantly reduced the increase in TNF- $\alpha\left(B g n^{+/ 0}, 43 \% \pm 13 \%\right.$; $B g n^{-/ 0}, 76 \% \pm 14 \%$; percentage of inhibition calculated for the respective sample stimulated with BGN without blocking antibodies, $n=3, P<0.05$ ) and MIP-2 levels 
A
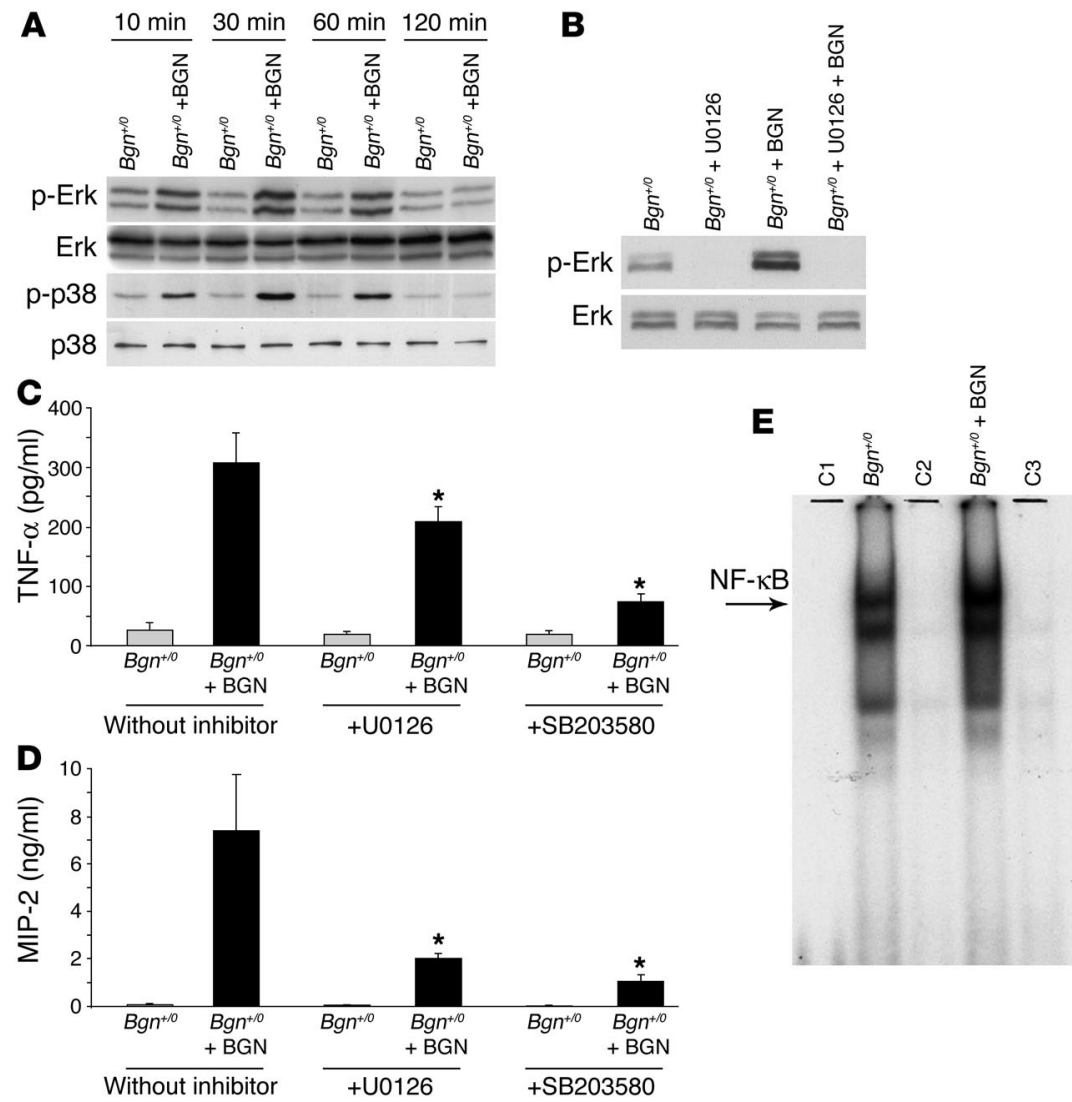

Figure 4

Activation of MAPKs and NF- $\mathrm{KB}$ by BGN in macrophages. (A) Phosphorylation of ERK and p38 in $B g n^{+/ 0}$ macrophages after 10-120 minutes of incubation with BGN (Western blots). (B) Effects of the MEK1/2 inhibitor (U0126) on the phosphorylation of ERK in $\mathrm{Bgn}^{+/ 0}$ macrophages 30 minutes after induction with BGN. (C and D) Reduced levels of TNF- $\alpha$ (C) and MIP-2 (D) in the presence of U0126 or SB203580 (an inhibitor of p38 MAPK) in culture media from $\mathrm{Bgn}^{+/ 0}$ macrophages 6 hours after induction with BGN $(4 \mu \mathrm{g} / \mathrm{ml})$. Data are given as means \pm SD from 3-4 animals in each group. ${ }^{*} P<0.05$ for macrophages with BGN and inhibitor versus macrophages with BGN and without inhibitor. (E) Electrophoretic mobility shift assay of nuclear extracts from $\mathrm{Bgn}^{+/ 0}$ macrophages cultured for 30 minutes with or without BGN. C1 to C3 represent negative controls: $\mathrm{C} 1$, without protein; C2 and C3, macrophages with 100 times free oligonucleotides and without (C2) or with BGN (C3).
$\left(B g n^{+/ 0}, 34 \% \pm 6 \% ; B g n^{-/ 0}, 55 \% \pm 23 \%\right.$; percentage of inhibition, $n=3$, $P<0.05)$ in culture media upon BGN stimulation after 6 hours.

Furthermore, incubation of $B g n^{-/ 0}$ macrophages with intact human BGN in the presence of a cross-linker and subsequent immunoprecipitation with anti-BGN antiserum showed that BGN coimmunoprecipitates with both TLR4 (Figure 5D) and TLR2 (Figure 5E). Electrospray ionization tandem mass spectrometry (ESI/MS/MS) analysis of 2 bands migrating at $42-44 \mathrm{kDa}$ and a band at $96 \mathrm{kDa}$ of the immunoprecipitate after digestion with chondroitinase $\mathrm{ABC}$ and separation by $1 \mathrm{D}$ gel electrophoresis (Figure $5 \mathrm{~F}$ ) identified human BGN with a probability-based score of 221 (Figure 5G) and a sequence coverage of 13\% (Figure 5H) and mouse TLR4 with a probability-based score of 528 (Figure 5I) and a sequence coverage of $8 \%$ (Figure $5 \mathrm{~J}$ ). Individual ion scores greater than 46 indicate identity or extensive homology $(P<0.05)$. Other significant hits (Figure 5, G and I) represented mainly keratins and trypsin. Note that band 2 (Figure 5F) was at the limit of detection, which is probably why TLR2 was not detected by ESI/MS/MS.

By gel filtration we could demonstrate interaction of BGN with a high-molecular weight complex containing TLR4 and/or TLR2, MD-2, and CD14 as shown in Supplemental Figure 2.

Effects of BGN on phosphorylation of ERK and p38 were tested after 30 minutes in macrophages from WT (C57BL/6) mice, TLR2-/- mice, $\mathrm{C} 3 \mathrm{H} / \mathrm{HeJ}$ mice hyporesponsive to LPS because of a point mutation in the TLR4 gene $(T L R 4-M)(26,37), T L R 2^{-1-} /$ TLR4-M mice, and MyD88 $8^{-/-}$mice (shown for ERK in Figure 6A). Deficiency in either TLR2 or MyD88 as well as mutation in TLR4 markedly diminished BGN-mediated phosphorylation of ERK, while functional lack of both TLRs completely abolished phos- phorylation (Figure 6B). These data provide evidence for differential signaling between BGN $(4 \mu \mathrm{g} / \mathrm{ml})$ and LPS $(2 \mathrm{ng} / \mathrm{ml})$, since LPS-mediated signaling was completely abolished in TLR4-M macrophages whereas BGN was still able to increase phosphorylation of ERK via TLR2 (Figure 6, A and B). Another difference was observed in $M y D 88^{-/-}$macrophages, where BGN-mediated phosphorylation of ERK was strongly reduced (Figure 6, A and B), while LPS could still stimulate ERK via a MyD88-independent pathway (Figure 6A; WT plus LPS: $5.4 \pm 0.8$ times control without LPS; $M y D 88^{-/-}$plus LPS: $3.8 \pm 0.5$ times control without LPS; each $n=3, P<0.05)$. In agreement with this signaling pattern, BGN-induced increases in the levels of secreted TNF- $\alpha$ and MIP-2 were slightly reduced in TLR2-/-, markedly decreased in TLR4- $M$ and $M y D 88^{-/-}$, and completely abrogated in TLR2-/TLR4- $M$ macrophages (Figure 6, C and D). Finally, BGN-mediated activation of NF- $\mathrm{KB}$ was detected by EMSA in HEK293 cells transfected with human TLR4/MD-2/CD14 (Figure 6E). These data suggest that $\mathrm{BGN}$ is signaling in macrophages mainly through TLR4 in a MyD88-dependent manner, causing activation of NF- $\mathrm{KB}$ and MAPKs. Besides TLR4, TLR2 is also involved in BGNmediated signaling in macrophages.

To ensure that activation of macrophages by BGN was not attributable to contamination of the BGN preparation, we carefully ruled out the presence of LPS, other proinflammatory factors, and other TLR4 and TLR2 ligands (Supplemental Figure 3).

Since in TLR2-/-/TLR4-M macrophages an inflammatory response to $\mathrm{BGN}$ was completely abolished, the role of alternative receptors is very unlikely. However, as interactions of BGN with the SR-A type I (SR-AI) and the endocytic mannose receptor have 
A

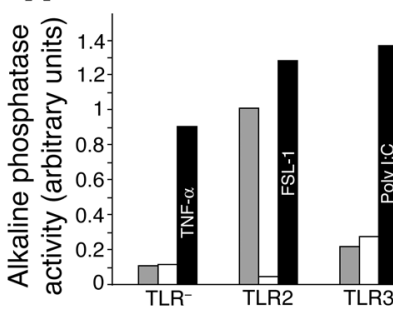

TLR4

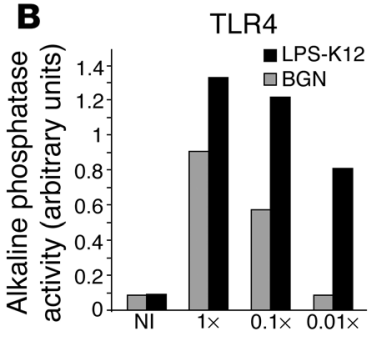

C

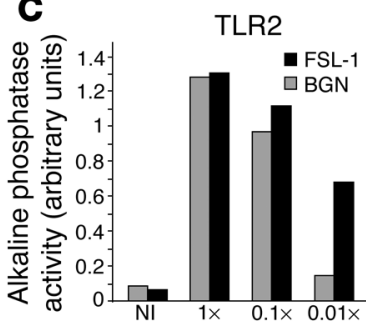

G

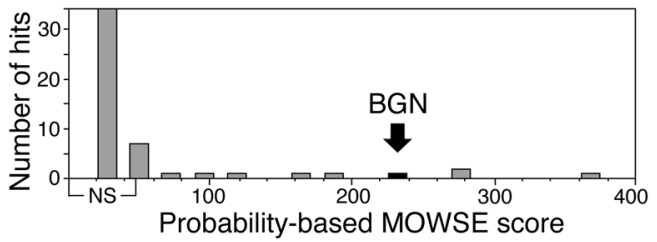

H

Sequence coverage: $13 \%$

1 MWPLWRLVSL LALSQALPFE QRGFWDFTLD DGPEMMNDEE ASGADTSGVL 51 DPDSVTPTYS AMCPFGCHCH LRVVQCSDLG LKSVPKEISP DTTLLDLQNN 101 DISELRKDDF KGLQHLYALV LVNNKISKIH EKAFSPLRKL QKLYISKNHL 151 VEIPPNLPSS LVELR IHDNR IRKVPKGVFS GLRNMNCIEM GGNPLENSGE 201 EPGAFDGLKL NYLRISEAKL TGIPKDLPET LNELHLDHNK IQA.IELEDLL 251 RYSKLYRLGL GHNQIRMIEN GSLSFLPTLR ELHLDNNKLA. RVPSGLPDLK 301 LLQVVYLHSN NITKVGVNDE CPMGFGVKRA YYNGISLENN PVPYWEVQPA 351 TFRCVTDRLA IQFGNYKK

I

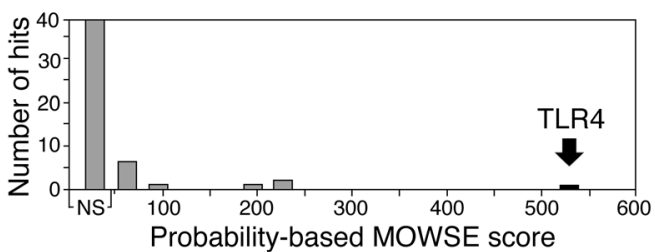

J

1 MMPPWLLART LIMALFF SCL TPGSLNPCIE VVPNITYQCM DQKLSKVPDD 51 IPSSTKNIDL SFNPLKILKS YSFSNFSELQ WLDLSRCEIE TIEDKAWHGL 101 HHLSNLILTG NPIQSESPGS FSGLTSLENL VAVETKLASL ESFPIGQLIT 151 LKKLNVAHNF IHSCKLPAYF SNLTNLVHVD LSYNYIQTIT VNDLQFLREN 201 PQVNLSLDIS LNPIDE IQDQ AFQG IKLHEL TLRGNENSSN IMKTCLQNLA 251 GLHIHRLILG EFKDERNLEI FEPSIMEGLC DVTIDEERLT YTNDFSDDIV 301 KF HCLANVAA MSLAGVSTKY LEDVKHE KW QSLSIIRCQL KQF PTLDLPF 作

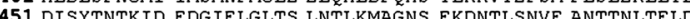
551 DYNAD FGIFGLTS LNTLMAGN 作 601 VEOMTCATY EMNTSVLAF FNLTNNSVAC TCEHQKE L QW VKDRKQFLVN 651 VEXFHITIA GMNTKSVLDE NNSTCYMYKT IISVSVVSVI VVSTVAFLIY 701 FHLCLHYRDF IPGVAIAAN I IOEGE HKSRK VIVVVSRHEI OSRLECTEYR 751 IAQTWOFLSS HSGIIF IVLE KVEKSLLRQQ VELYRLLSRN TYLENEDNPI 801 GRHIFWRRLK NALLDGKASN PEQTAEEEOE TATWT

\section{Figure 5}

Interaction of BGN with TLR4 and TLR2 in macrophages. (A) Screening for BGN-induced (10 $\mu \mathrm{g} / \mathrm{ml})$ activation of NF-kB in 293-TLR cells expressing only 1 type of TLR and alkaline phosphatase as reporter gene (gray bars). An HEK293 cell line expressing only the reporter gene was used as control (TLR-). As positive control, each cell line was induced with a specific ligand (black bars). Noninduced TLR clones were used as negative controls (white bars). TLR activation is shown as activity of the secreted alkaline phosphatase in arbitrary units. (B and C) Doseresponse analysis of the effect of BGN (gray bars; 1× equals $10 \mu \mathrm{g} / \mathrm{ml}$ ) on the activation of TLR4 (B) and TLR2 (C). "Nl" indicates a noninduced TLR cell line. Black bars represent positive controls (1x equals $100 \mathrm{ng} / \mathrm{ml}$ of LPS-K12 or FSL-1). (D and E) Immunoprecipitation for BGN after incubation of $\mathrm{Bgn}^{-10}$ or $T L R 4^{-/-}$(D) or $T L R 2^{-/-}$macrophages (E) with BGN $(4 \mu \mathrm{g} / \mathrm{ml})$ in the presence of a cross-linker, followed by Western blot for TLR4 (D, top panel) or TLR2 (E, top panel). The bottom panels represent Western blots for BGN core protein after chondroitinase ABC treatment. (F) Colloidal Coomassie G250-stained SDS-PAGE indicating bands obtained by immunoprecipitation and analyzed by ESI/MS/MS. (G-J) ESI/MS/MS of bands labeled in $\mathbf{F}$ as $1(\mathbf{G}$ and $\mathbf{H})$ and 2 (I and $\mathbf{J})$ recognized human BGN with a probability-based score of 221 (G) and with a sequence coverage of $13 \%(\mathrm{H})$ and mouse TLR4 with a probability-based score of $528(\mathrm{I})$ and with a sequence coverage of $8 \%(\mathrm{~J})$. MOWSE, molecular weight search.

been reported $(21,22)$, we excluded a role of these receptors in BGN signaling (Supplemental Figure 4).

Prolonged survival of Bgn-deficient mice in zymosan-induced sepsis but not in T cell-mediated lethal shock triggered by the superantigen staphylococcal enterotoxin $B$. To test whether TLR2-mediated activation of macrophages is relevant in vivo, zymosan-induced sepsis (38) was evaluated in $B g n^{-/ 0}$ and $B g n^{+/ 0}$ mice. $B g n^{-/ 0}$ mice revealed improved survival (Figure 7A), lower plasma levels of TNF- $\alpha$ (Figure 7B), and a reduced number of $\mathrm{H} \& \mathrm{E}$ - and $\mathrm{F} 4 / 80$-positive infiltrating cells in septic lungs (Table 1). Finally, we induced a lethal shock syndrome triggered by staphylococcal enterotoxin B (SEB) in $B g n^{-/ 0}$ and $B g n^{+/ 0}$ mice sensitized by D-galactosamine hydrochloride. The basic differences between this model and LPS- or zymosaninduced sepsis are that SEB triggers activation of T lymphocytes, not macrophages, and that this model does not involve TLRs (39). In this model, survival (Figure 7C), plasma levels of TNF- $\alpha$ (Figure
7D), and the number of infiltrating mononuclear cells in the lungs $\left(B g n^{+/ 0}, 3.6 \pm 0.5 ; \mathrm{Bgn}^{-/ 0}, 3.9 \pm 0.9 ; \mathrm{Bgn}^{+/ 0}\right.$ plus SEB, $4.8 \pm 1.5 ; B g n^{-/ 0}$ plus SEB, $3.8 \pm 0.5$; H\&E, $n=4, P>0.05$ ) did not differ between $B g n^{-/ 0}$ and $B g n^{+/ 0}$ mice. Thus, these data provide further evidence for a role of macrophages and TLR4 and TLR2 in BGN-associated inflammatory processes.

\section{Discussion}

In the present studies, we have identified a new role of BGN as a crucial proinflammatory factor. The most convincing evidence for the biological relevance of this finding is the observation that Bgn-null mice have a considerable survival benefit compared with WT animals, both in LPS-induced and in zymosan-induced sepsis, due to a mitigated inflammatory response that results in less end-organ damage. This survival benefit in Bgn-null mice is probably due to the fact that the initial sequence of inflammatory 

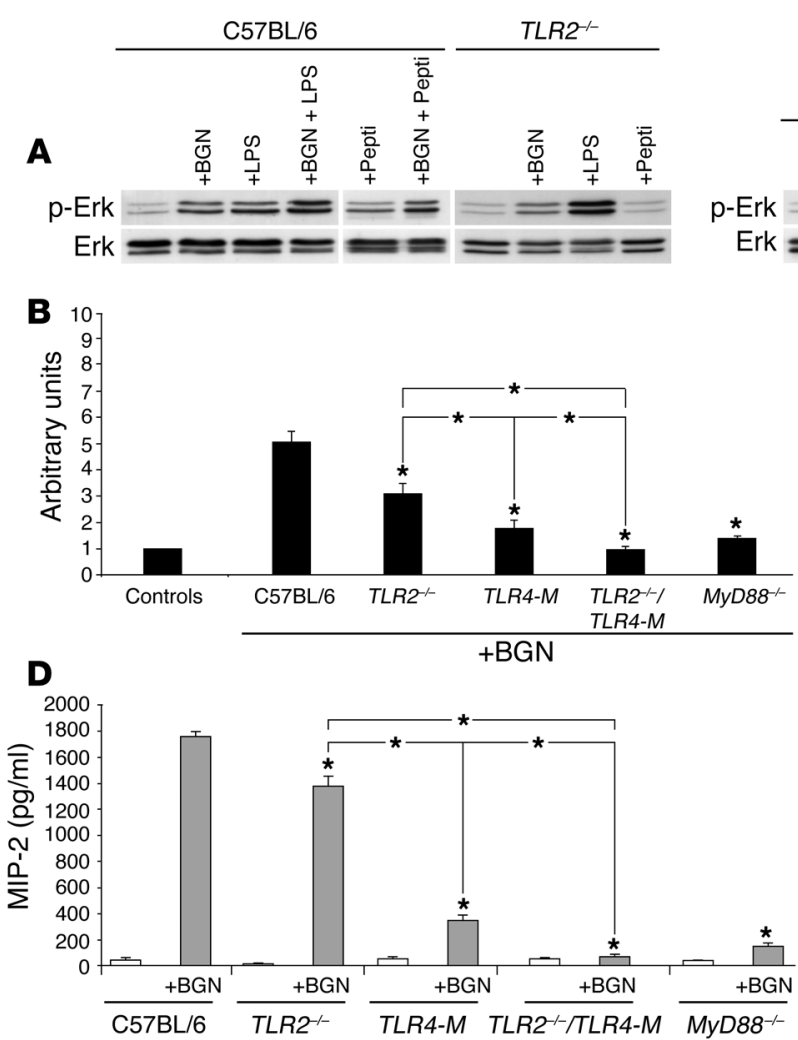

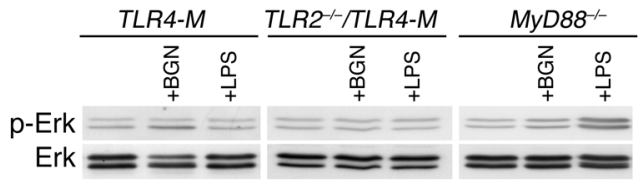

C 180

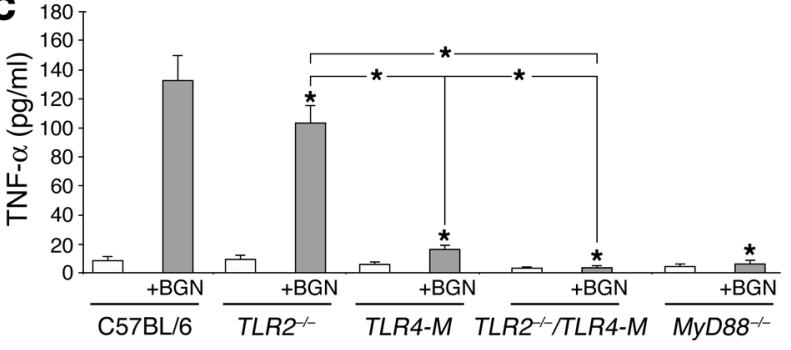

E

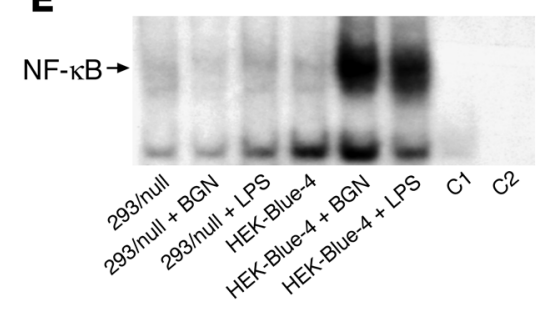

\section{Figure 6}

Absence of BGN-mediated stimulation of ERK, TNF- $\alpha$, and MIP-2 in TLR2-I-/TLR4-M macrophages and reduced stimulation in macrophages

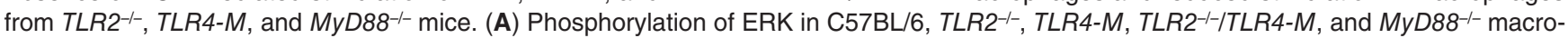
phages 30 minutes after incubation with BGN $(4 \mu \mathrm{g} / \mathrm{ml})$, LPS $(2 \mathrm{ng} / \mathrm{ml})$, or peptidoglycan (Pepti) $(5 \mu \mathrm{g} / \mathrm{ml})$ (Western blots). (B) Densitometric quantification of $p$-ERK/ERK ratio in macrophages indicated in A. Controls represent macrophages without BGN and are defined as 1 arbitrary unit. Data are given as means \pm SD from 3 Western blots. (C and D) ELISA for TNF- $\alpha$ (C) and MIP-2 (D) in media from macrophages indicated in A after 6 hours of culture without or with BGN $(4 \mu \mathrm{g} / \mathrm{ml})$. Data are given as means \pm SD from $7-8$ animals in each group. Significant differences for TLR- or MyD88-deficient versus C57BL/6 macrophages incubated with BGN are indicated by an asterisk positioned over the respective bar: ${ }^{*} P<0.05$. (E) BGN- or LPS-mediated $(2 \mathrm{ng} / \mathrm{ml}$ ) activation of NF- $\mathrm{kB}$, detected after 30 minutes by EMSA in HEK-Blue-4 cells (transfected with human TLR4/MD-2/CD14 genes) versus 293/null cells. C1 (macrophages with 500 times free oligonucleotides) and C2 (without nuclear extract) represent negative controls.

events, namely PAMP-triggered expression of proinflammatory factors such as IL-1 $\beta$ and IL-6, subsequent IL-1 $\beta /$ IL- 6 -induced expression of BGN in macrophages, and finally BGN-induced expression of TNF- $\alpha$, is interrupted in the absence of BGN. The relevance of this interpretation of our data is underscored by the observation that the increased secretion of IL- $1 \beta$ and IL- 6 as an initial response to LPS is indistinguishable in Bgn-deficient and WT macrophages, while the subsequent TNF- $\alpha$ production is significantly reduced in the Bgn-deficient macrophages because of the lack of costimulatory effects of BGN. Regulation of TNF- $\alpha$ by BGN has not been reported previously, although in lung fibroblasts TNF- $\alpha$ has been proven to induce the expression of BGN (40). Since the initial release of TNF- $\alpha$ is of critical importance for the outcome of sepsis, therapeutic strategies to neutralize this cytokine have been developed, but no clear-cut survival benefits have been achieved so far (41). This study demonstrates that in the early stages of sepsis, serum levels of TNF- $\alpha$ are considerably lower in Bgn-deficient than in WT mice.

The importance of BGN during sepsis is underlined by the fact that BGN overexpression could be observed in septic lungs, at both mRNA and protein levels. Early upregulation of BGN in pul- monary inflammation has already been reported $(42,43)$; however, its biological relevance remained unclear. We previously observed a striking concurrence of BGN overexpression and enhanced numbers of infiltrating cells in a model of renal inflammation (14). In the present study we confirmed this relationship in the lung and addressed the potential mechanism in vitro by showing that BGN, besides TNF- $\alpha$, induces the expression of MIP-2, a potent chemoattractant of infiltrating cells (44). Enhanced numbers of macrophages were in fact triggered by BGN, since other ECM components, such as fibronectin, laminin, and types I and VI collagen, which could potentially increase monocyte sticking $(34,35)$, were upregulated to the same extent in lungs from septic $B g n^{+/ 0}$ and $B g n^{-10}$ mice. BGN regulates lung fibroblast migration via stimulation of the small GTPases RhoA and Rac1 (6). Interestingly, both the Rho proteins and the p38 MAPK pathways have been shown to be important mediators of LPS-induced expression of IL-8, a human MIP-2 homolog, in human endothelial cells (45).

It is particularly noteworthy that macrophages, seminal cells of the innate immune system (24), are capable of producing BGN upon stimulation by proinflammatory factors. Previously, we have shown that macrophages do contain and secrete BGN in a 

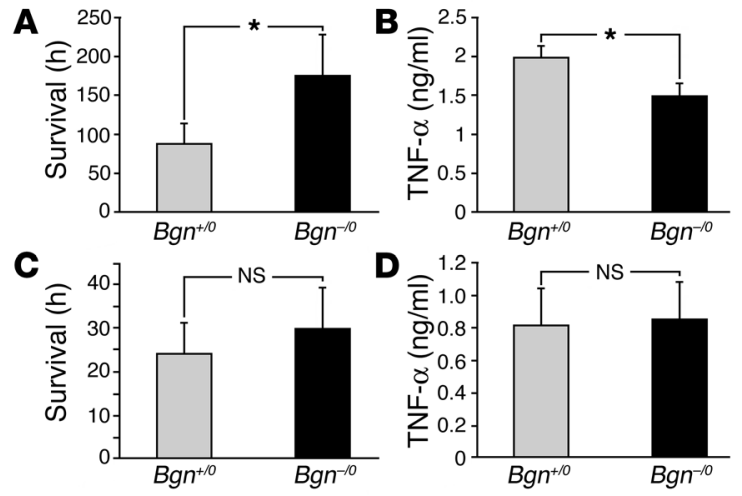

Figure 7

Survival and plasma levels of TNF- $\alpha$ in zymosan- or superantigen SEB-induced sepsis. Bgn deficiency improved survival (A) and lowered plasma levels of TNF- $\alpha(\mathbf{B})$ in mice with zymosan-induced sepsis but did not affect $T$ cell-mediated lethal shock triggered in mice by the superantigen SEB (C and D). (A) Survival of male $\mathrm{Bgn}^{-10}$ and $\mathrm{Bgn}^{+/ 0}$ $(n=5)$ mice after a lethal dose of zymosan A. (B) Plasma levels of TNF- $\alpha$ in $\mathrm{Bgn}^{+/ 0}$ and $\mathrm{Bgn}^{-10}$ mice $(n=5) 5$ hours after a lethal dose of zymosan A. (C and D) Survival $(n=6)(\mathbf{C})$ and plasma levels of TNF- $\alpha$ $(n=7)$ (D) 90 minutes after a lethal dose of SEB simultaneously injected with D-galactosamine hydrochloride in $\mathrm{Bgn}^{-10}$ and $\mathrm{Bgn}^{+/ 0}$ mice. There were no differences in the plasma levels of TNF- $\alpha$ between zymosan- and SEB-free mice (data not shown). ${ }^{*} P<0.05$.

model of renal inflammation (14). A recent study reported BGN in association with macrophages in human gingiva (46). In the present investigation, we found that unstimulated peritoneal macrophages do not express BGN. However, once activated by IL- 6 and IL-1 $\beta$, macrophages start to express BGN mRNA and secrete the proteoglycan into the culture medium. Although the presence of an IL- 6 -responsive element in the BGN promoter region has been reported (36), the IL-1 $\beta$ - and IL-6-triggered expression of BGN in macrophages is, to our knowledge, a novel finding. The fact that macrophages produce BGN only upon inflammatory stimulation underlines the biological importance of this proteoglycan in terms of its influence on inflammation. As only soluble BGN is active in stimulating macrophages, presumably because in the immobilized state the binding sites for macrophage receptors are inaccessible because of binding of BGN to other ECM components, we suggest that regulation is achieved via the amount of BGN liberated from immobilized pools by the activity of proteolytic enzymes in the course of sepsis, rather than via fine-tuning of BGN expression levels. Thus, only Bgn-null mice could be seen to have a survival benefit in sepsis, which suggests that, in heterozygous females, sufficiently high tissue content of $\mathrm{BGN}$ is present to support macrophage activation.

Our data showing that BGN interacts with TLR4 and to a lesser extent with TLR2, and the subsequent predominantly MyD88dependent induction of ERK, p38, and NF- $\mathrm{KB}$, significantly extend the knowledge of the biology of BGN for 2 reasons: (a) the data confirm that BGN acts as a signaling molecule, and (b) they firmly establish this proteoglycan as an integral part of the innate immune system. Although the involvement of BGN in various signaling processes has been addressed $(4-6,15,33)$, this is, to our knowledge, the first report to provide evidence for BGN-mediated signal transduction in macrophages, starting from the initial receptors and describing the downstream signaling events and the inflam- matory mediators subsequently generated. Various structural molecules have been reported to modulate an inflammatory response reaction $(9-13,47)$. Glycosaminoglycan (GAG) chains are well known to act as targets for bacterial, viral, and parasitic virulence factors for attachment, invasion, and immune evasion (48-50). In our study, only intact BGN and to a lesser extent the intact decorin molecule were able to deliver a proinflammatory signal to macrophages. Thus, BGN-mediated stimulation of macrophages is not due to a general effect of GAG chains but was shown to be in fact BGN-specific. Recent studies demonstrated that ECM components, previously only regarded as docking sites for microbial pathogens, might actively participate in immune defense as an integral part of the innate immune system $(9,11-13)$. Among these ECM molecules, fibronectin extra domain A (11) and hyaluronan-derived oligosaccharides (9) have been shown to activate TLR4. Our study provides evidence that the ECM component BGN is also actively involved in the innate immune response. In contrast to hyaluronan $(9,13)$, BGN strongly influences the effector phase of an immune reaction (e.g., increase in activity of macrophages).

BGN effectively uses the TLR signaling cascade by binding to both TLR4 and TLR2. Contaminations are unlikely to have caused the effects. Apart from the neutralizing activity of antibodies directed against BGN, which strongly implicates BGN as the active component, contaminatory products have been excluded by several assays as outlined in the supplemental material. Most importantly, our data show a clear survival benefit of Bgn-null mice in TLR4- and TLR2-dependent models of sepsis but not in SEB-mediated shock, where T lymphocytes and not macrophages are triggered in a TLR-independent way (39). Further evidence for BGN-specific TLR4- and TLR2-mediated proinflammatory effects is provided by the observation that BGN and LPS signal differently in TLR4-M and $M y D 88^{-/-}$macrophages. The fact that BGN-induced signaling in macrophages is mediated by 2 receptors important in the recognition of both Gram-negative $(26-28,37)$ and Gram-positive pathogens (24) emphasizes the key role of this proteoglycan within the innate immune system.

In summary, our results demonstrate the biological relevance of BGN in a prototypical innate immune process such as sepsis and identify a novel role of BGN as a crucial proinflammatory factor. Being ubiquitously present in the ECM, BGN can be liberated during inflammation by proteolytic enzymes, or alternatively be induced in macrophages by PAMP-triggered cytokines, to signal through the classical PAMP receptors TLR4 and TLR2. Subsequent expression of TNF- $\alpha$ and MIP-2 will cause recruitment of more macrophages, which also will start to produce BGN, creating a feed-forward cycle that is able to drive an inflammatory response forward in both an autocrine and a paracrine manner.

\section{Methods}

Mice. Female $\mathrm{Bgn}^{-/-}$and $\mathrm{Bgn}^{-/+}$and male $\mathrm{Bg} n^{-/ 0}, \mathrm{Bg} n^{+/+}$, and $\mathrm{Bg} n^{+/ 0}$ mice (C57BL/6) have been previously described (3). Since the Bgn gene is located on the $\mathrm{X}$ chromosome, male animals have only 1 allele. TLR4-M mice with a TLR4 gene point mutation $(\mathrm{C} 3 \mathrm{H} / \mathrm{HeJ})(26,37)$ and TLR4 WT strains $(\mathrm{C} 3 \mathrm{H} /$ $\mathrm{HeN}$ ) were from Charles River Laboratories. TLR2 $2^{-/}$and $T L R 4^{-/-}$mice were kindly provided by M. Freudenberg (Max Planck Institute for Immunology, Freiburg, Germany), TLR4-M/TLR2-/- mice by C.J. Kirschning (Institute of Medical Microbiology, Immunology, and Hygiene, Technical University of

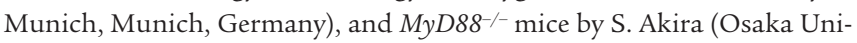
versity, Osaka, Japan). Sepsis was induced by i.p. injection into 8-week-old mice of $200 \mu \mathrm{g} / \mathrm{g}$ body weight ( $\mu \mathrm{g} / \mathrm{g}$ b.wt.) or $45 \mu \mathrm{g} / \mathrm{g}$ b.wt. (sublethal dose) 
of LPS from Salmonella minnesota, trichloroacetic acid extracted from S. minnesota (Sigma-Aldrich), or ultrapure S. minnesota (InvivoGen). Zymosan A (Sigma-Aldrich) prepared in $0.9 \% \mathrm{NaCl}$ as described previously (38) and endotoxin-tested was injected i.p. in a dose of $2 \mathrm{mg} / \mathrm{g}$ b.wt. (a lethal dose in 8-week-old $\mathrm{Bgn}^{+/ 0}$ mice). D-Galactosamine hydrochloride ( $4 \mathrm{mg} / \mathrm{g}$ b.wt. i.p.; Carl Roth $\mathrm{GmbH})$ and the superantigen SEB $(10 \mu \mathrm{g} / \mathrm{g}$ b.wt. in hind footpads; Sigma-Aldrich) were injected simultaneously (39) in 8-week-old Bgn-10 and $B g n^{+/ 0}$ mice. Mean body weights were not different between groups. All animal work was done in accordance with the German Animal Protection Law and was approved by the Ethics Review Committee for laboratory animals of the District Government of Muenster, Germany.

Cell culture and stimulation. Macrophages were harvested by peritoneal lavage 5 days after injection of thioglycollate, and cultured in RPMI 1640 (Invitrogen Corp.) under serum-free conditions. Only adherent cells were used for primary cultures. Purity was controlled by flow cytometry and Giemsa staining. LPS, cell culture-tested, from S. minnesota and peptidoglycan from Staphylococcus aureus were both from Sigma-Aldrich. Ultrapure LPS from S. minnesota was from InvivoGen. To control responsiveness, cells from each isolation were stimulated with LPS $(0.1 \mathrm{ng} / \mathrm{ml})$ and/or peptidoglycan $(5 \mu \mathrm{g} / \mathrm{ml})$ for 2 hours and tested for secreted TNF- $\alpha$. Intact BGN, BGN core protein, or $B G N$-derived GAG chains were used in concentrations of $1-10 \mu \mathrm{g} / \mathrm{ml}$. If it is not indicated otherwise, experiments were done with $4 \mu \mathrm{g} / \mathrm{ml}$ of BGN. When required, macrophages were preincubated for 30 minutes with rat anti-mouse TLR4 blocking antibodies ( $40 \mu \mathrm{g} / \mathrm{ml}$; Imgenex) recognizing the TLR4/MD-2 complex, or for 1 hour with $10 \mu \mathrm{M}$ of MEK1/2 inhibitor (U0126; Cell Signaling Technology) or p38 MAPK inhibitor (SB203580; Sigma-Aldrich). Stimulation of macrophages was performed with recombinant mouse IL-1 $\beta$ (10 ng/ml; Sigma-Aldrich) or human IL-6 (10 ng/ml; R\&D Systems).

HEK293 cells stably transfected with pNIFTY2-SEAP vectors containing human TLR4, MD-2, and CD14 genes (HEK-Blue-4) or human TLR2 and CD14 genes (TLR2/CD14) and 293/null (control) cells (all from InvivoGen) were cultured according to the manufacturer's instructions.

Northern blot analysis, RT-PCR, and in situ bybridization. Total RNA was extracted using TRIzol (Invitrogen Corp.). Membranes were hybridized with ${ }^{32} \mathrm{P}-$ labeled cDNA probes for BGN (51), TNF- $\alpha$ (American Type Culture Collection), and MIP-2 (52). A mouse $\alpha$-tubulin probe encompassing bp 365-965 (GenBank accession number M13446), generated by RT-PCR (53) with the primer pair 5'-AAGGAGGATGCTGCCAATAA-3' and $5^{\prime}$ AGAGATCACCAATGCCTGCT-3', was used to control for equal loading. Northern blots were performed and quantified as described previously (53). RT-PCR for BGN and GAPDH and in situ hybridization for BGN were described previously (51).

Western blotting and ELISA. Western and dot blots were performed and quantified as described previously (53). The following antibodies were used: rabbit anti-human TLR4 cross-reacting with mouse TLR4, and rabbit anti- $\beta$-tubulin (both from Santa Cruz Biotechnology Inc.); rabbit antimouse TLR2 and rabbit anti-human TLR2 (both from Imgenex Corp.); rabbit anti-mouse pan-laminin and rabbit anti-human fibronectin (both from Sigma-Aldrich); and rabbit antibodies against phosphorylated and total ERK (Thr202/204) and p38 (Thr180/Tyr182) MAPK (all from Cell Signaling Technology). BGN core protein from murine lungs was semipurified and quantified by dot blotting using LF-106, a rabbit anti-murine BGN antiserum kindly provided by L.W. Fisher (National Institute of Dental and Craniofacial Research) (54), as described previously (53). Dot blot results were confirmed by Western blotting and standardized to the content of $\beta$-tubulin in the samples before purification. TNF- $\alpha$, MIP-2, IL- 6 , and IL- $1 \beta$ were measured in plasma, culture media, and homogenates of macrophages by mouse-specific ELISAs (R\&D Systems). Results were normalized by protein content and cell number. All assays were performed in duplicate, and each experiment was carried out at least 3 times.
Activation of TLRs by BGN. BGN-induced stimulation via TLR2, -3, -4, -5, $-7,-8$, or -9 was tested in HEK293 cells expressing only 1 type of TLR and secreted alkaline phosphatase under the control of a modified human IL-12p40 promoter inducible by NF- $\mathrm{kB}$, activator protein-1, and IFN-regulatory factors cloned into PNIFTY2-SEAP vectors. The amount of secreted alkaline phosphatase was determined using the SEAP Reporter Assay Kit (measurements were performed by TLR screening service of InvivoGen) and is given as arbitrary units. Screening was performed (in duplicate) by challenge of the 7 TLR clones with $10 \mu \mathrm{g} / \mathrm{ml}$ of BGN and comparison of the induced alkaline phosphatase activity to that of negative controls (respective noninduced TLR clones) and that of positive controls stimulated with the following ligands: FSL-1 $(10 \mathrm{ng} / \mathrm{ml})$ for TLR2, poly I:C $(10 \mu \mathrm{g} / \mathrm{ml})$ for TLR3, LPS-K12 (10 and $1 \mathrm{ng} / \mathrm{ml})$ for TLR4, flagellin $(100 \mathrm{ng} / \mathrm{ml})$ for TLR5, R848 $(1 \mu \mathrm{g} / \mathrm{ml})$ for TLR7 and -8 , and ODN $2006(10 \mu \mathrm{g} / \mathrm{ml})$ for TLR9 (InvivoGen). Dose-response analysis was performed (in triplicate) using BGN $(10 \mu \mathrm{g} / \mathrm{ml}, 1 \mu \mathrm{g} / \mathrm{ml}, 0.1 \mu \mathrm{g} / \mathrm{ml})$ on the respective TLR cell lines.

Immunoprecipitation and protein identification by ESI/MS/MS. Immunoprecipitation of human BGN was performed as described previously (55) with some modifications. Thioglycollate-elicited Bgn $n^{-/ 0}$, TLR2 $2^{-/}$,

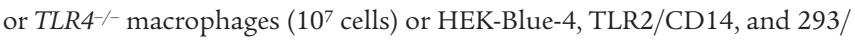
null cells were incubated with $8 \mu$ g of intact human BGN for 2 hours at $4^{\circ} \mathrm{C}$ and then with $1 \mathrm{mM} 3,3^{\prime}$-dithiobis(sulfo-succinimidyl propionate) (DTSSP; Pierce Biotechnology Inc.) for cross-linking of BGN to binding proteins. Cells were harvested in radioimmunoprecipitation (RIPA) buffer, and a complex of normal rabbit serum bound to protein A-Sepharose (Sigma-Aldrich) was added for 6 hours to remove nonspecifically precipitated proteins. Then $10 \mu \mathrm{g}$ of rabbit anti-human BGN (55) was added, and after 16 hours the immune complexes were precipitated with protein A-Sepharose. As control, a similar amount of protein A-Sepharose was incubated with the antibody but without cell lysate. Additional controls included samples incubated without cross-linker and/or without BGN. After washing (3 times in lysis buffer, twice in PBS), the material containing intact BGN was divided into 2 aliquots. One aliquot was treated with chondroitinase $\mathrm{ABC}$. Bound proteins were eluted by boiling in the respective sample buffer (55). Some immunoprecipitations for BGN were performed using rabbit IgG TrueBlot (eBioscience) according to the manufacturer's suggestion. Samples were examined by Western blotting for the presence of TLR 4 and BGN, using BGN core protein and homogenates of TLR2 $2^{-1-}$ and TLR4 $4^{-/-}$macrophages, HEK-Blue-4, TLR2/ CD14, and 293/null cells as positive or negative controls. After separation by 1D SDS gel electrophoresis, identification of human BGN and mouse TLR4 by proteomics service (MS-ESI-PROTID; Eurogentec) using ESI/MS/MS was performed in $B g n^{-10}$ macrophages incubated with BGN, immunoprecipitated for $\mathrm{BGN}$, and digested with chondroitinase $\mathrm{ABC}$. Results were analyzed by a Mascot database search (Matrix Science Ltd.).

Morphology and immunohistochemistry. Formaldehyde- or zinc-fixed and paraffin-embedded lung tissue sections were stained for matrix antigens and mononuclear cells by immunoperoxidase, alkaline phosphatase, anti-alkaline phosphatase, or streptavidin/biotin-alkaline phosphatase techniques $(51,52)$. Primary antibodies included LF-113, a rabbit anti-murine decorin antiserum (54), LF-106 (1:500), rabbit anti-mouse fibromodulin (1:100) (33), rabbit anti-rat type I collagen (1:50; Quartett $\mathrm{GmbH})$, rabbit anti-human fibronectin (1:200; Sigma-Aldrich), biotinylated goat anti-type VI collagen (1:20; Southern Biotechnology Associates Inc.), and, for populations of monocytes/ macrophages, rat anti-mouse F4/80 (1:2,000; BD Biosciences - Pharmingen). Double-immunostaining for BGN (chicken anti-rat BGN) (51) and F4/80 was performed as described previously (56). Immunolabeled and H\&E-stained mononuclear cells were counted by a blinded observer in 15 high-power fields $(\times 400)$ per section and recorded as mean per high-power field.

Other procedures. Expression of human BGN and decorin in HEK293 cells and purification of the native proteoglycans were described previously 
$(33,57)$. Potential contamination of BGN preparations was ruled out as described in the supplemental material.

Nuclear extraction was performed with NucBuster Protein Extraction Kit (EMD Biosciences Inc.) and analyzed by EMSA. Briefly, $2.5 \mu \mathrm{g}$ of nuclear protein was incubated with $40 \mathrm{kcpm}$ of ${ }^{32} \mathrm{P}$-labeled oligonucleotide coding for the region of interest. Reactions were incubated for 45 minutes on ice. For oligonucleotide competition, $20 \mathrm{ng}$ of specific oligonucleotide competitor was added prior to the probe. Oligonucleotide sequences for consensus or mutant DNA-binding domains were purchased from Santa Cruz Biotechnology Inc. (NF-кB/sc2505/sc2511).

Protein concentrations were determined using the BCA Protein Assay Reagent (Pierce Biotechnology Inc.).

Statistics. Data are given as means \pm SD analyzed by 1-way ANOVA, with Dunnett's significance correction test (SPSS 13.0; SPSS Inc.). Differences were considered significant at a $P$ value of less than 0.05 .

\section{Acknowledgments}

This work has been supported by the Deutsche Forschungsgemeinschaft (SFB 492, B10 to L. Schaefer and R.M. Schaefer; SFB 405,
B10 to H.-J. Gröne; and GO1392/1-1 to M. Götte), the University of Muenster (Interdisciplinary Center of Clinical Research, Muenster, Schae2/004/04 and IMF SC 110407 to L. Schaefer and R.M. Schaefer), and the Austrian Science Fund (FWF, P17013-B05-MED to E. Malle). We are grateful to Monty Krieger (Massachusetts Institute of Technology, Cambridge, Massachusetts, USA) for providing control and CHO-SR-AI cells. We are grateful to B. Arnold (German Cancer Research Center), P.J. Nelson (University of Munich, Munich, Germany), and D. Vestweber (University of Muenster) for their critical reading of the manuscript. The technical support of Siegmund Budny, Martina Volz, and Claudia Schmidt is highly appreciated.

Received for publication October 27, 2004, and accepted in revised form May 24, 2005.

Address correspondence to: Liliana Schaefer, Medizinische Klinik und Poliklinik D, Universitätsklinikum Muenster, Albert-Schweitzer-Strasse 33, 48149 Muenster, Germany. Phone: 49-251-8347525; Fax: 49-251-86-9550; E-mail: schaefl@uni-muenster.de.
1. Iozzo, R. 1999. The biology of the small leucine-rich proteoglycans: functional network of interactive proteins [review]. J. Biol. Chem. 274:18843-18846.

2. Ameye, L., et al. 2002. Abnormal collagen fibrils in tendons of biglycan/fibromodulin-deficient mice lead to gait impairment, ectopic ossification, and osteoarthritis. FASEB J. 16:673-680.

3. Xu, T., et al. 1998. Targeted disruption of the biglycan gene leads to an osteoporosis-like phenotype in mice. Nat. Genet. 20:78-82.

4. Moreno, M., et al. 2005. Biglycan is a new extracellular component of the Chordin-BMP4 signaling pathway. EMBO J. 24:1397-1405.

5. Weber, C., et al. 2001. Biglycan is overexpressed in pancreatic cancer and induces G1-arrest in pancreatic cancer cell lines. Gastroenterology. 121:657-667.

6. Tufvesson, E., and Westergren-Thorsson, G. 2003. Biglycan and decorin induce morphological and cytoskeletal changes involving signalling by the small GTPases RhoA and Rac1 resulting in lung fibroblast migration. J. Cell Sci. 116:4857-4864.

7. Sime, P.J., et al. 1997. Adenovirus-mediated gene transfer of the proteoglycan biglycan induces fibroblastic responses in the lung [abstract]. Chest. 111(Suppl. 6): 137S

8. Nathan, C. 2002. Points of control in inflammation. Nature. 420:846-852.

9. Termeer, C., et al. 2002. Oligosaccharides of hyaluronan activate dendritic cells via toll-like receptor 4 . J. Exp. Med. 195:99-111.

10. Comalada, M., et al. 2003. Decorin reverses the repressive effect of autocrine-produced TGF- $\beta$ on mouse macrophage activation. J. Immunol. 170:4450-4456.

11. Okamura, Y., et al. 2001. The extra domain A of fibronectin activates Toll-like receptor 4. J. Biol. Chem. 276:10229-10233.

12. He, Y.W., et al. 2004. The extracellular matrix protein mindin is a pattern-recognition molecule for microbial pathogens. Nat. Immunol. 5:88-97.

13. Jameson, J.M., Cauvi, G., Sharp, L.L., Witherden, D.A., and Havran, W.L. 2005. Gammadelta T cell-induced hyaluronan production by epithelial cells regulates inflammation. J. Exp. Med. 201:1269-1279.

14. Schaefer, L., et al. 2002. Absence of decorin adversely influences tubulointerstitial fibrosis of the obstructed kidney by enhanced apoptosis and increased inflammatory reaction. Am. J. Pathol. 160:1181-1191.

15. Schaefer, L., et al. 2003. Biglycan, a nitric oxide-regulated gene, affects adhesion, growth, and survival of mesangial cells. J. Biol. Chem. 278:26227-26237.

16. Hildebrand, A., et al. 1994. Interaction of the small interstitial proteoglycans biglycan, decorin and fibromodulin with transforming growth factor- $\beta$. Biochem. J. 302:527-534.

17. Tufvesson, E., and Westergren-Thorsson, G. 2002. Tumour necrosis factor-alpha interacts with biglycan and decorin. FEBS Lett. 530:124-128.

18. Kikuchi, A., et al. 2000. Haemopoietic biglycan produced by brain cells stimulates growth of microglial cells. J. Neuroimmunol. 106:78-86.

19. Bell, J.K., et al. 2003. Leucine-rich repeats and pathogen recognition in Toll-like receptors [review]. Trends Immunol. 24:528-533.

20. O'Neill, L.A. 2002. Toll-like receptor signal transduction and the tailoring of innate immunity: a role for Mal [review]? Trends Immunol. 23:296-300.

21. Santiago-Garcia, J., Kodama, T., and Pitas, R.E. 2003 The class A scavenger receptor binds to proteoglycans and mediates adhesion of macrophages to the extracellular matrix. J. Biol. Chem. 278:6942-6946.

22. Chieppa, M., et al. 2003. Cross-linking of the mannose receptor on monocyte-derived dendritic cells activates an anti-inflammatory immunosuppressive program. J. Immunol. 171:4552-4560.

23. Medzhitov, R., and Janeway, C., Jr. 2000. Innate immunity. N. Engl. J. Med. 343:338-344.

24. Beutler, B. 2004. Inferences, questions and possibilities in Toll-like receptor signalling [review]. Nature. 430:257-263.

25. Janeway, C.A., Jr., and Medzhitov, R. 2002. Innate immune recognition. Annu. Rev. Immunol. 20:197-216.

26. Poltorak, A., et al. 1998. Defective LPS signaling in $\mathrm{C} 3 \mathrm{H} / \mathrm{HeJ}$ and $\mathrm{C} 57 \mathrm{BL} / 10 \mathrm{ScCr}$ mice: mutations in Tlr4 gene. Science. 282:2085-2088.

27. Medzhitov, R., Preston-Hurlburt, P., and Janeway, J.C. 1997. A human homologue of the Drosophila Toll protein signals activation of adaptive immunity. Nature. 388:394-397.

28. Wright, S. 1999. Toll, a new piece in the puzzle of innate immunity. J. Exp. Med. 189:605-609.

29. Takeda, K., and Akira, S. 2005. Toll-like receptors in innate immunity. Int. Immunol. 17:1-14.

30. Reimann, T., et al. 1994. Lipopolysaccharide induces activation of the Raf-1/MAP kinase pathway. J. Immunol. 153:5740-5749.

31. Baldassare, J., Bi, Y., and Bellone, C. 1999. The role of p38 mitogen-activated protein kinase in IL-1 transcription. J. Immunol. 162:5367-5373.

32. Cohen, J. 2002. The immunopathogenesis of sep- sis. Nature. 420:885-891.

33. Schaefer, L., et al. 2004. Regulation of fibrillin- 1 by biglycan and decorin is important for tissue preservation in the kidney during pressure-induced injury. Am. J. Pathol. 165:383-396.

34. Alon, R., et al. 1994. TNF-alpha binds to the $\mathrm{N}$-terminal domain of fibronectin and augments the beta 1-integrin-mediated adhesion of CD4+ $\mathrm{T}$ lymphocytes to the glycoprotein. J. Immunol. 152:1304-1313.

35. Hershkoviz, R., Goldkorn, I., and Lider, O. 1995. Tumour necrosis factor-alpha interacts with laminin and functions as a pro-adhesive cytokine. Immunology. 85:125-130.

36. Ungefroren, H., and Krull, N.B. 1996. Transcriptional regulation of the human biglycan gene. J. Biol. Chem. 271:15787-15795.

37. Qureshi, S., et al. 1999. Endotoxin-tolerant mice have mutations in Toll-like receptor 4 (Tlr4) [erratum 1999, 189:following 1518]. J. Exp. Med. 189:615-625.

38. Minter, R.M., et al. 2001. Adenoviral delivery of human and viral IL-10 in murine sepsis. J. Immunol. 167:1053-1059.

39. Miethke, T., et al. 1992. T cell-mediated lethal shock triggered in mice by the superantigen staphylococcal enterotoxin B: critical role of tumor necrosis factor. J. Exp. Med. 175:91-98.

40. Tufvesson, E., and Westergren-Thorsson, G. 2000. Alteration of proteoglycan synthesis in human lung fibroblasts induced by interleukin-1beta and tumor necrosis factor-alpha. J. Cell. Biochem. 77:298-309.

41. Reinhart, K., and Karzai, W. 2001. Anti-tumor necrosis factor therapy in sepsis: update on clinical trials and lessons learned [review]. Crit. Care Med. 29(Suppl. 7):S121-S125.

42. Westergren-Thorsson, G., et al. 1993. Altered expression of small proteoglycans, collagen, and transforming growth factor-beta 1 in developing bleomycin-induced pulmonary fibrosis in rats. J. Clin. Invest. 92:632-637.

43. Venkatesan, N., Ebihara, T., Roughley, P.J., and Ludwig, M.S. 2000. Alterations in large and small proteoglycans in bleomycin-induced pulmonary fibrosis in rats. Am. J. Respir. Crit. Care Med. 161:2066-2073.

44. Guo, R.F., and Ward, P.A. 2002. Mediators and regulation of neutrophil accumulation in inflammatory responses in lung: insights from the IgG immune complex model [review]. Free Radic. Biol. Med. 33:303-310. 
45. Hippenstiel, S., et al. 2000. Rho proteins and the p38-MAPK pathway are important mediators for LPS-induced interleukin-8 expression in human endothelial cells. Blood. 95:3044-3051.

46. Alimohamad, H., Habijanac, T., Larjava, H., and Hakkinen, L. 2005. Colocalization of the collagen-binding proteoglycans decorin, biglycan, fibromodulin and lumican with different cells in human gingiva. J. Periodontal Res. 40:73-86.

47. Mor-Vaknin, N., Punturieri, A., Sitwala, K., and Markovitz, D. 2003. Vimentin is secreted by activated macrophages. Nat. Cell Biol. 5:59-63.

48. Rostand, K.S., and Esko, J.D. 1997. Microbial adherence to and invasion through proteoglycans. Infect. Immun. 65:1-8.

49. Feizi, T. 2000. Carbohydrate-mediated recogni- tion systems in innate immunity. Immunol. Rev. 173:79-88.

50. Trowbridge, J.M., and Gallo, R.L. 2002. Dermatan sulfate: new functions from an old glycosaminoglycan [review]. Glycobiology. 12:117R-125R.

51. Schaefer, L., et al. 1998. Decorin, biglycan and their endocytosis receptor in rat renal cortex. Kidney Int. 54:1529-1541.

52. Walpen, S., et al. 2001. Nitric oxide induces MIP-2 transcription in rat renal mesangial cells and in a rat model of glomerulonephritis. FASEB J. 15:571-573.

53. Schaefer, L., et al. 2001. Small proteoglycans in human diabetic nephropathy: discrepancy between glomerular expression and protein accumulation of decorin, biglycan, lumican, and fibromodulin. FASEB J. 15:559-561.
54. Fisher, L., Stubbs, J., and Young, M. 1995. Antisera and cDNA probes to human and certain animal model bone matrix noncollagenous proteins. Acta Orthop. Scand. Suppl. 266:61-65.

55. Hausser, H., Ober, B., Quentin-Hoffmann, E., Schmidt, B., and Kresse, H. 1992. Endocytosis of different members of the small chondroitin/dermatan sulfate proteoglycan family. J. Biol. Chem. 267:11559-11564.

56. Grone, H.J., et al. 2002. Spatial and temporally restricted expression of chemokines and chemokine receptors in the developing human kidney. J. Am. Soc. Nephrol. 13:957-967.

57. Kresse, H., et al. 2001. Different usage of the glycosaminoglycan attachment sites of biglycan. J. Biol. Chem. 276:13411-13416. 